www.jmscr.igmpublication.org

Impact Factor 5.84

Index Copernicus Value: 83.27

ISSN (e)-2347-176x ISSN (p) 2455-0450

crossref DOI: _https://dx.doi.org/10.18535/jmscr/v5i5.214

\author{
Journal Of Medical Science And Clinical Research \\ IGM Publication \\ An official Publication of IGM Publication
}

\title{
Effectiveness of Steroid Therapy in Newborns with Meconium Aspiration Syndrome
}

\author{
Authors \\ Dr Sangeetha. $\mathbf{T}^{\mathbf{1}}$, Dr Ramanathan. $\mathbf{R}^{2}$, Dr Yogavalli.S $\mathbf{3}^{3}$ \\ ${ }^{* 1}$ MD- Post Graduate, Department of Pediatrics, Rajah Muthiah Medical College, Chidambaram \\ ${ }^{2}$ Associate Professor, Department of Pediatrics, Rajah Muthiah Medical College, Chidambaram \\ ${ }^{3}$ DCH -Post Graduate, Department of Pediatrics, Rajah Muthiah Medical College, Chidambaram
}

\begin{abstract}
Objective: Meconium aspiration syndrome (MAS) is one of the serious and life-threatening disorders in newborn infants and is still one of the most challenged neonatal diseases. This study was conducted in order to determine the efficacy of steroid use in the management of this syndrome.

Study Design \& Period and Place of study: A prospective study of twelve months period in the neonatal intensive care unit was carried out at Rajah Muthiah Medical College \& Hospital, Chidambaram.

Materials and Methods: We included Sixty (60) babies with MAS which were then distributed randomly into two groups i.e. Group A $(n=30)$, patients in this group served as controls and Group $B(n=30)$, patients who were treated with steroids served as study group. Injectable dexamethasone was administered @ $0.5 \mathrm{mg} / \mathrm{kg} /$ dose $q 12 \mathrm{~h}$ for the first 3 days \& $0.25 \mathrm{mg} / \mathrm{kg} /$ dose $q-12-\mathrm{h}$ for the next 4 days along with supportive treatment. Non steroid group received only supportive care (control group). Infants in present trial were evaluated on the basis of duration of stay at hospital, requirement of ventilatory support and occurrence of pneumothorax.

Results: We observed a statistically significant difference in the duration of stay between the two groups. There was also a difference in the requirement of ventilator support and occurrence of pneumothorax in the study, but it was not statistically significant.

Conclusion: The conclusion of our study is that steroids revealed shorter duration of stay, less ventilator requirement and less morbidity in newborns with MAS. Thus steroid therapy has a favourable effect on the outcome on MAS in newborn.

Keywords: Meconium aspiration syndrome, Newborn infants, Steroids.
\end{abstract}

\section{INTRODUCTION}

Meconium aspiration syndrome (MAS) is often characterized as disease of the term and post-term infants and is correlated with considerable respiratory morbidity and mortality. ${ }^{1}$ The MAS incidence rate has been reported to be 1-2/1000 live births in the well-developed countries; however, this number must be greater in the developing world. ${ }^{2,3}$ In addition to acute impact, it can also have serious chronic impact on the respiratory system ${ }^{2}$ of new born.

Despite many control measures to prevent MAS, many newborn still develop MAS and thus need some proper treatment. MAS is thus the commonest life threatening emergency in term babies all over the world. About one-third of infants with MAS require intubation and mechanical ventilation ${ }^{4}$ MAS is generally difficult 
to handle despite an enhanced understanding of its mechanism and the available therapeutic approaches. Therefore, a large number of alternative practices have been tested to successfully manage it. Use of steroids with the prime objective of managing MAS has been widely accepted although there are many sound critics of their use because of doubts regarding their effectiveness and fear of side effects. The pioneer work done in this regard was not too much encouraging, however a favorable and encouraging effect of this therapy was reported later by many authors. $^{7,8,9}$ For example, Ward et al. in 2003 reported, after conducting the analyses of two trials with a total of 85 infants who were having MAS, that there was no significant effect of steroids on mortality although there was a slight decrease in the oxygen treatment period in patients treated with steroids. ${ }^{7}$ Later on, Basu et al and Tripathi et al., continued their research work in this direction. Both of them reported in their trials that use of steroids in babies with MAS was significantly correlated with a reduced duration of oxygen therapy and hospital stay and other morbidities as well. ${ }^{8,9}$ The type of steroid, way of administration and period of steroid use had different results in their trials. They concluded that steroids may be helpful in extreme MAS conditions such as lung edema, pulmonary vasoconstriction, and inflammation. Presently, there is no rural study carried out in this direction putting forth some idea of effectiveness of steroid therapy in babies with MAS. ${ }^{10}$

The objective of the study was to evaluate whether steroid use helps modifying the clinical course of MAS and improves the outcome without causing any side effects.

\section{MATERIALS \& METHODS}

We carried out a prospective and interventional study over twelve months period in neonatal intensive care unit of Rajah Muthiah medical college \& hospital, Annamalai University. This study was approved by the institutional ethical committee.
Inclusion criteria

- All Term neonates with MAS admitted in Neonatal Intensive care unit were included in the study

\section{Exclusion criteria}

- We excluded Neonates with major congenital anomalies, those with suspected Congenital Heart Disease and those with risk of sepsis from the study.

\section{METHODOLOGY}

A total of 60 neonates were included in this study. 30 were randomly placed in group A (Control) and rest of the 30 in group B (treated with steroids). All the 30 patients of group B (Steroid group) were treated with standard regimens of steroid- Inj.dexamethasone $0.5 \mathrm{mg} / \mathrm{kg} / \mathrm{dose} \mathrm{q} 12 \mathrm{~h}$ for the first 3 days $\& 0.25 \mathrm{mg} / \mathrm{kg} /$ dose $\mathrm{q}-12$-h for the next 4 days -totally for seven days intravenously. Except for this intervention, management of all the neonates was done according to the standard protocol of the neonatal intensive care unit during the study period.

Outcome measures for our study were measured by length of hospitalization, occurrence of Pneumothorax, and requirement of mechanical ventilation.

\section{Statistical analyses}

The descriptive statistical analysis included examinations of mean, standard deviations, frequencies, ranges, and percentages. The statistical packages SPSS (Version 20) and MS Excel (MS Office 2010) were used. Student's t test was applied to see the difference between control and steroid group.

\section{RESULTS}

In total, 60 patients met all study inclusion criteria, and their parents agreed to participate in the study. These babies were divided randomly into two groups i.e. Group A (Control) and Group B (Steroids). Results of this randomized control trial showed significant difference in the length of hospitalization in the steroid group as compared to those who were not treated with the steroids. 
Figure 1- clearly shows the difference between two groups as patients in steroid group had a mean stay of 3.19 days at hospital as compared to control group that had a mean stay of 3.6 days. This difference between the two groups showed the efficacy of steroid therapy in babies with MAS.

Table 1: Duration of hospital stay between the two groups

\begin{tabular}{|l|c|c|c|}
\hline $\begin{array}{l}\text { Mean hospital } \\
\text { stay }\end{array}$ & Non-Steroid & Steroid & Total \\
\hline$<3$ days & $4(13.3 \%)$ & $8(26.7 \%)$ & $\begin{array}{c}12 \\
(20 \%)\end{array}$ \\
\hline $3-7$ days & $26(86.7 \%)$ & $\begin{array}{c}22 \\
(73.3 \%)\end{array}$ & $\begin{array}{c}48 \\
(40 \%)\end{array}$ \\
\hline TOTAL & $30(100 \%)$ & $\begin{array}{c}30 \\
(100 \%)\end{array}$ & $\begin{array}{c}60 \\
(100 \%)\end{array}$ \\
\hline
\end{tabular}

Newborns treated with steroids recovered early and was discharged sooner than those in the non steroid group. The mean hospital stay was less in steroid group than the control group.

Table 2: Incidence of Pulmonary Air-Leak Syndrome

\begin{tabular}{|l|c|c|c|}
\hline $\begin{array}{l}\text { Pulmonary } \\
\text { air leak }\end{array}$ & $\begin{array}{c}\text { Non- } \\
\text { Steroid }\end{array}$ & Steroid & Total \\
\hline No & $\begin{array}{c}28 \\
(93.3 \%)\end{array}$ & $\begin{array}{c}29 \\
(96.7 \%)\end{array}$ & $\begin{array}{c}57 \\
(95 \%)\end{array}$ \\
\hline Yes & $\begin{array}{c}2 \\
(6.7 \%)\end{array}$ & $\begin{array}{c}1 \\
(3.3 \%)\end{array}$ & $\begin{array}{c}3 \\
(5 \%)\end{array}$ \\
\hline Total & $\begin{array}{c}30 \\
(100 \%)\end{array}$ & $30(100 \%)$ & $\begin{array}{c}60 \\
(100 \%)\end{array}$ \\
\hline
\end{tabular}

The incidence of Air Leak Syndromes was only $3 \%$ in Steroid group, while in Non Steroid group it was $7 \%$. There was decrease in occurrence of Air Leaks in the neonates treated with steroids, though it was not statistically significant ( $\mathrm{p}$ value $>0.005)$.

Table 3: Need for Ventilator Support in Both Groups:

\begin{tabular}{|l|c|c|c|}
\hline Ventilator support & Non-Steroid & Steroid & Total \\
\hline Not Required & $21(70 \%)$ & $\begin{array}{c}25 \\
(83.3 \%)\end{array}$ & $46(76.7 \%)$ \\
\hline Required & $\begin{array}{c}9 \\
(30 \%)\end{array}$ & $\begin{array}{c}5 \\
(16.7 \%)\end{array}$ & $14(23.3 \%)$ \\
\hline Total & 30 & 30 & 60 \\
\hline
\end{tabular}

The requirement of ventilator support in the Steroid group was $17 \%$ while that of Non-Steroid group was $30 \%$. The requirement of ventilator support in steroid group was less but no statistically significant difference was observed between both the groups. ( $p$ value $>0.005$ ).

\section{DISCUSSION}

Appropriate resuscitation and management in newborn with meconium aspiration can reduce significantly the incidence and prevalence of MAS. But despite all control measures and efforts, a considerable number of babies develop MAS. Currently, the core area of MAS management in most of the hospitals is only the supportive care. Through an enhanced understanding of the MAS mechanism, this study reports the possibility of altering the adverse outcome of the disease by using steroids to reduce the chemical and inflammatory pneumonitis caused by Meconium. Role of steroids is well established in many pulmonary conditions and is instrumental in decreasing morbidity and mortality. This is the one of the first studies which was carried out in local settings of Pakistan to investigate the effect of steroid use in newborns with meconium aspiration syndrome.

In our study we found a significant reduction in the duration of hospital stay in the babies who were treated with steroid compared to those who were in control group. Our results are in afreement with Tripathi et al. ${ }^{9}$ who also found considerable reduction in hospital stay in steroid treated patients as compared to control ones. There has been a lot of debate and valid concern over complications due to use of steroids in newborn infants (both short-term and long-term effects).

Laforce and Brudno ${ }^{12}$ however, did not find any increased incidence of infections in their trial of beclomethasone steroid in infants of BPD. ${ }^{12}$ Barr $^{13}$ did not show any considerable increase in the incidence of any infection (sepsis, hypertension) in uncontrolled study on use of budesonide in newborn infants with severe respiratory impairements. ${ }^{13}$ By this time, none of the studies in the local settings of our country have shown any data regarding the adverse effects of steroids 
in infants with MAS. There was slight differences in the incidence of co-morbidities between the 2 groups. We showed that babies who were treated with steroids were having shorter stay at hospital than the control group. We also arrive at a conclusion, that the requirement of mechanical ventilation was less in those newborn treated with steroids than the control group. However, we recommend further studies in this direction in order to determine optimum steroid dose and to assess the duration/course of treatment, and ways of administration considering their characteristics and probable acute and chronic side effects ${ }^{10}$

\section{CONCLUSION}

In our study, steroids appeared to be effective in terms of reducing the morbidities, hospital stay \& ventilatory support in newborn infants with MAS. Moreover, there were no adverse effects of steroids with short term usage. At present, there is insufficient evidence to assess the effects of steroid therapy in the management of MAS. As meconium aspiration syndrome is a major cause of mortality, further studies highlighting proper dose of steroid, mode of administration and duration of treatment should be carried out in order to increase the effectiveness of steroids in the management of meconium aspiration syndrome.

\section{REFERENCES}

1. Wiswell TE, Tuggle JM, Turner BS. Meconium aspiration syndrome: have we made a difference? Pediatrics. 1990;85(5): 715-21.

2. Ross MG. Meconium aspiration syndrome- more than intrapartum meconium. New Eng. J. Med. 2005;353:946-48.

3. Swarnam K, Soraisham AS, Sivanandan S. Advances in the Management of Meconium Aspiration Syndrome. Int. J. Ped. 2012;1:7.

4. Dargaville PA, Copnell B. The epidemiology of meconium aspiration syndrome: incidence, risk factors, therapies and outcome. Pediatrics. 2006;117:1712-21.

5. Yoder BA, Kirsch EA, Barth Jr. WH, Gordon MC. Changing obstetric practices associated with decreasing incidence of meconium aspiration syndrome. Obstet Gynecol. 2002;99(5):731-9.

6. Qian L, Liu C, Zhuang W, et al. Neonatal respiratory failure: a 12-month clinical epidemiologic study from 2004 to 2005 in China. Pediatrics. 2008;121:1115-24.

7. Ward M, Sinn J. Steroid therapy for meconium aspiration syndrome in newborn infants. Cochrane Database of Systematic Reviews. 2003;4:251.

8. Basu S, Kumar A, Bhatia BD, Satya K, and Singh TB, "Role of steroids on the clinical course and outcome of meconium aspiration syndrome-a randomized controlled trial," J. Tropi. Pediatr, 2007;53 (5):331-7.

9. Tripathi S and Saili A, "The effect of steroids on the clinical course and outcome of neonates with meconium aspiration syndrome," J. Tropi. Pediatr, 2007;53 (1):8-12.

10. Mokra D, Mokry J. Glucocorticoids in the treatment of neonatal meconium aspiration syndrome. Eur J Pediatr. 2011;170(12): 1495-1505.

11. Barrington KJ. The adverse neurodevelopmental effects of post natal steroids in the preterm infant: a systemic review of RCTs. BMC Pediatr. 2001;1:1.

12. Laforce WR, Brudno DS. Controlled trial of beclomethasone dipropionate by nebulization in oxygen- and ventilator-dependent infants. J Pediatr. 1993;133: 285-8.

13. Barr P. The use of dexamethasone in full term infants with severe respiratory failure and pulmonary barotraumas.J Pediatr Child Health. 1991;27:366-9.

14. Naveed Akbar Hotiana, Sumaira Naveed, Asma Anwar, Rashid Mehmood A.P.M.C Vol: 9 No. 3 July-September 2015. 